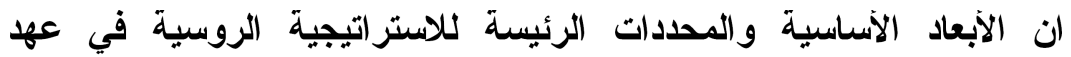

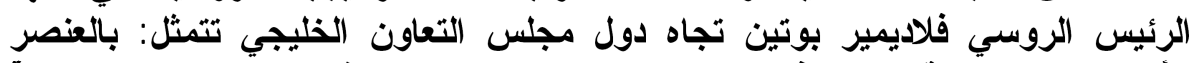

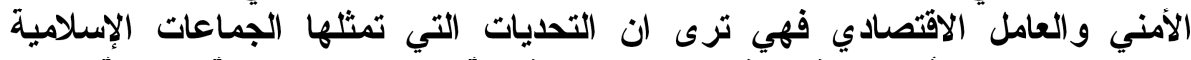

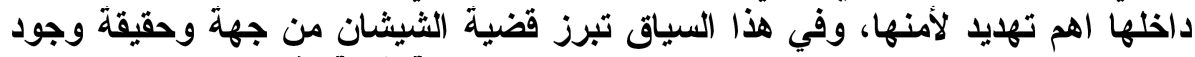

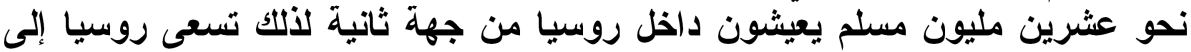

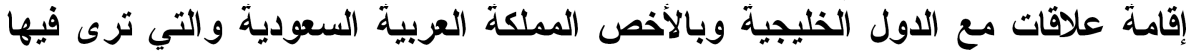
أنها ذات تأثثير كبير على هذه لأه الجماعات.

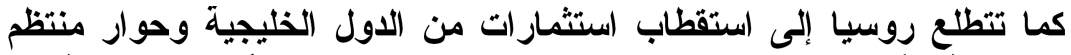

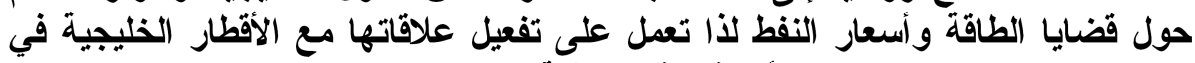
شتى المجالات من اجل تحقيق أهدافها في منطقة الخليج العربي.

(المقدمها

تنظر موسكو إلى منطقه الخليج العربي ضمن امن الــشرق الاوســط بـشكل

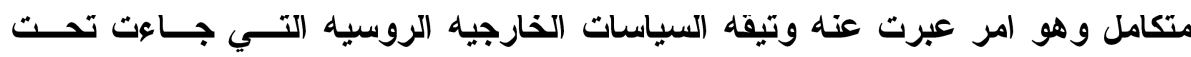

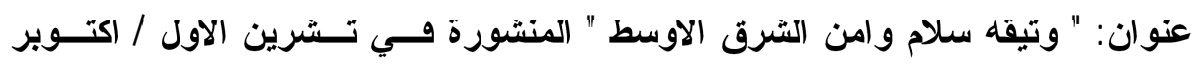

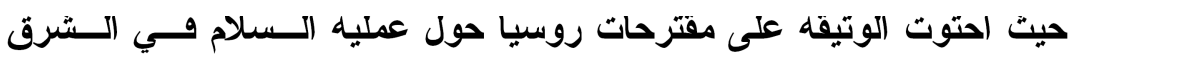
الاوسط وتوفير الامن في كل دول المنطقه. ولكن الوتيقه لم تتضمن ايه مقترحات خاصه

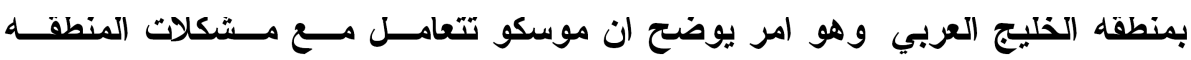
المرتبطه بمشكلات الشرق الاوسط ككل.

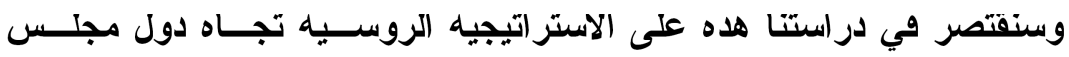

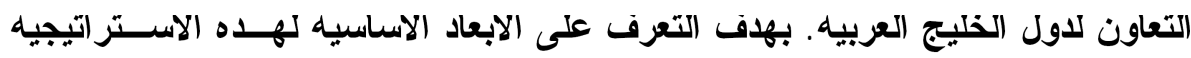

مدرس مساعد / فس الدراسات السياسيه والإستراتيجيه / مركز الدراسات الإفليميه / جامعه الموصل 
و المحددات الرئيسه لها في عهل الرئيس الروسي فلادمير بوتين، فـضلا عــن تطــور العلاهات بين الجانبين ومستقبل هده العلاهات خصوصا بعد الاحتلال الامريكي البريطاني

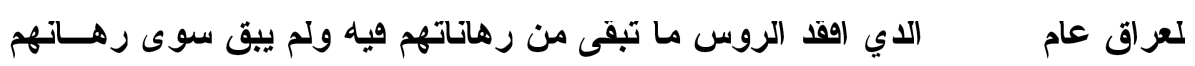
الاستر اتيجي على إيران.

اولا: تبدة تاريخيه

ترى مصادر تاريخيه عديلة ان علاهات روسيا بمنطقه الخليج العربـي ولايمـهـ تعود إلى ايام القياصرة وبالتحديد إلى النصف التاني من القرن التاسع عشر حين حاول الروس الآدهاع نحو الثرق عموما والخليج العربي بوجه خاص وهلا الآــدهاع كــان محكوما بوصيه بطرس الاكبر والتي جاء ويها!" توغلوا حتى تبلغــوا ســواحل الغـــيج

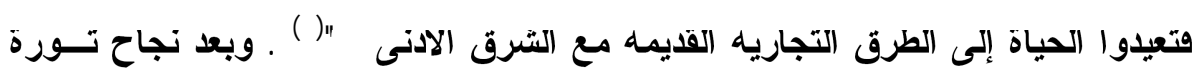
اكتوبر I9IV كان اهتمام القيادة الروسيه خلال المرحله الاولـى مـن حكـم الـــئيس السويتي ستالين ود انصب على تعزيز السلطه في إطار الحزب والدوله وتاكيـــ مبــــا

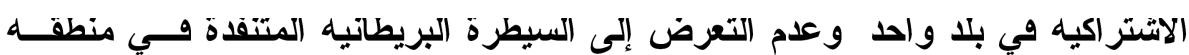

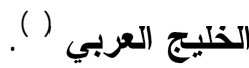

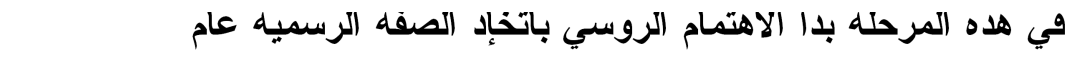

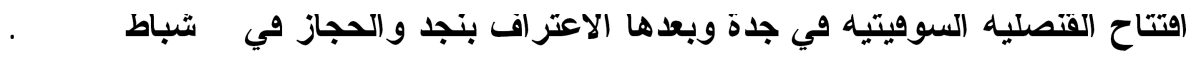

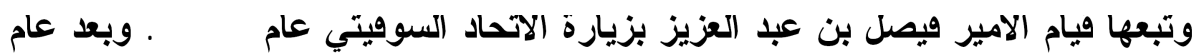

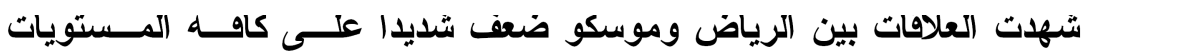

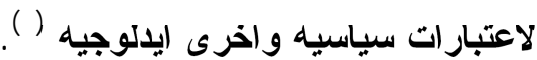
كاتت الكويت اسبق دول مجلس التعاون الخليجي بعد السعوديه وـــي اقامسـت

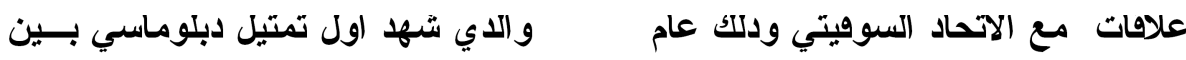

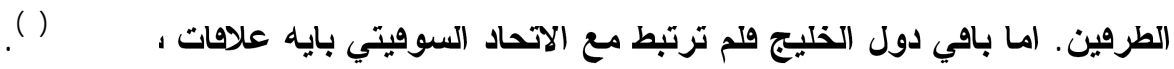


ولقد دوعت الاحدات لاحقا وبالاخص الحــرب العراويــه الإيراتيــه، والقـضيه

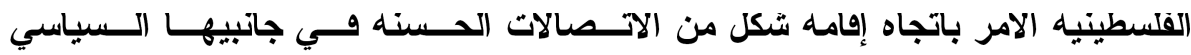
والاقتصادي بين موسكو واقطار مجلس التعاون الخليجي.إد اقامت كل من سلطنه عمان ودوله الإمارات العربيه المتحدة علافات دبلوماسيه مع الاتحاد السوفيتي في خريف عام 1910 إن سياسه الانفتاح التي اعلنها الرئيس السوفيتي ميخائيـلـ كورباتـشوفـف مي منتصف التماتينات من القرن الماضي والتي ادت إلى إحداث تغيرات وي مواوف موسكو تجاه القضايا الدوليه وفي علافاتها مع العالم الخارجي إد كاتت للمواققه السوهيتيه على

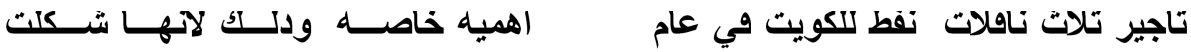
المشاركه السوفيتيه الاولى في دور يتعلق بامن الخليج(7). ومن التكتكيات التي استخدمها كورباتشوف لدوع مصالح بلاده مع الخليج إلـى الامام، عرض تعاون مع منظمه الاهطار المصدرة للنفط (اوبك) وفد ابلى عن رغبـتهم تلك من خلال الزيارات التي فام بها كل من وزير التفط الإيراني ووزير التفط الـسعودي تم وزير الخارجيه السعودي بنهايه عقد التمانينات من القرن المنصرم كما وــام وزيـر الخارجيه السعودي سعود الفيصل بزيارة الاتحاد السوهيتي كرئيس لوفد مجلس التعاون لاول الخليج العربيه وهبل دلك استضاقه السعوديه لقاء تم بين نائب وزيــر الخارجيـهـ

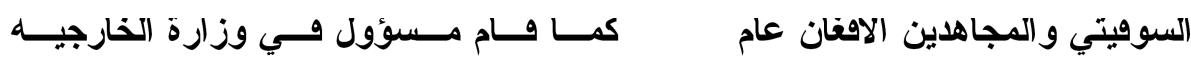
السوفيتيه وي زيارة الرياض في هده القترة. وفي IV / ايلــول ·199 تمـــ إعـادة

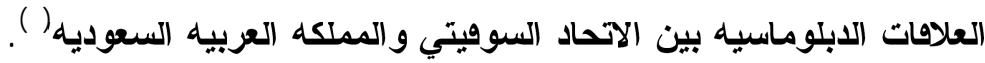
كاتت إعادة العلافات هي تلك الفترة سببه عدة متغير ات على الساحه العالميــه منها ورار الاتسحاب السوفيتي من اهغاتستان، والتطورات الاخليه السوفيتيه واحـــات اب عام •199 في منطقه الخليج العربي، والوضع الدولي. 
اما البحرين وقد عادت العلاهات مع روسيا وي تموز 1991). تانيا: محددات الإستر اتيجيه الروسيه

$$
\text { الموقع الجغر افي }
$$

يشكل العامل الجغرافي احد المحددات الرئيسه للاستر اتيجيه الروسـيه إد تعـد

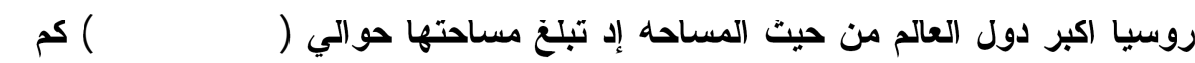

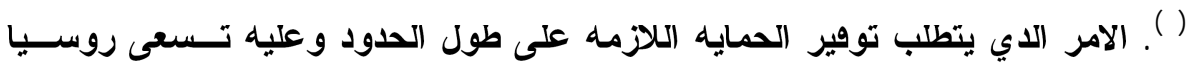
لإحامه علافات جيدة مع دول الجوار بغض النظر عن توجهات النظام السياسي.لاسب يمايما بعد وصول نقود حلف الشمال الاطلسي إلى الدول التي كاتت خاضعه للاتحاد السوفيتي.

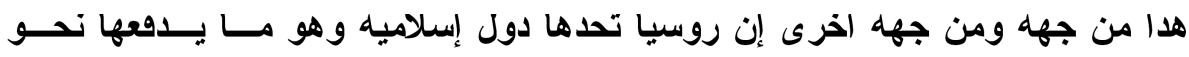
مر اوبه الدول الإسلاميه ودور الاسلام ويها اليوم وصد بدات ايضا تنظر إلى منطقه الخليج

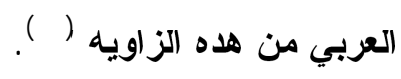

المصالح الوطنيه

تعتبر المصالح الوطنيه للاول الكبرى الاساس في اي تعامل وهي تسعى دائمس

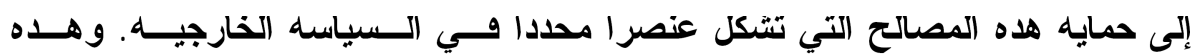

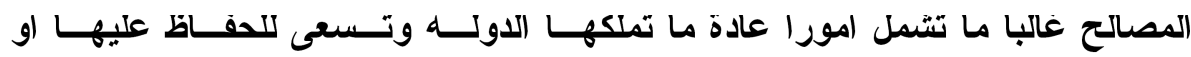
تهمينها(11) لالك فان الحكومه القائمه لن تتردد وي ان تعمل اي شي من اجل المحافظه عل مكلنتها ونقودها وول كان هدف الرئيس الروسي ولادمير بوتين ومند توليه السلطه

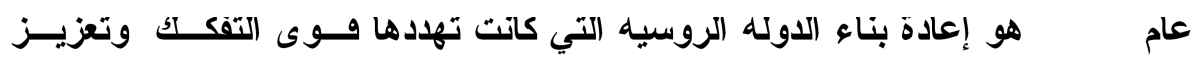
فبضه موسكو في المناطق التي تكون فيها الجماعات الإسلاميه دات نشاط اكبر خصوصا لهابه

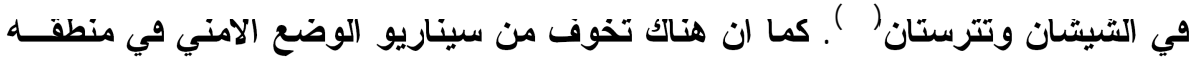
الشرق الاوسط وتداعياته ود تضر بمنطقه القوهاز واسيا الوسطى، وربما روسيا نقسها هنيا 
تتيجه لالك تطرح رؤاها وتـسهم بجهودهــا الابلوماسـيه لتحقيـق الاسـتقرار وـي (المنطقة) (Ir). ولان العنصر الامني يعد جزءا مهما من المحــددات فــي العلاهــات العربيـهـ الروسيه. صان روسيا ترى وي التحليات التي تمتلها الجماعات الإسلاميه داخل روسـيا تفسها اهم تهديا لا منها وفي هدا السياق تبرز وضيه الشيشان من جهه وحقيقه وجود تحو .م مليون مسلم يعيشون داخل روسيا من جهه تاتيه(ع). لالك يعمل الرئيس الروسي فلادمير بوتين على البحث عن دور اكتر فعاليه وي منطقه الخليج العربي و إفامه علاهات وديه مع دوله متل المملكه العربيه السعوديه والتي يرى إنها دات تاتير كبيسر علــى هـده (10) (10) العامل الاقتصادي تكتسب منطقه الخليج وشبه الجزيرة العربيه. اهميه اقتـــاديه إلــى جانـب اهميتها الجغر اهيه. وهو الامر الدي جعلها تحظى باهيه الدول الكبرى ولاسيما روسـيا

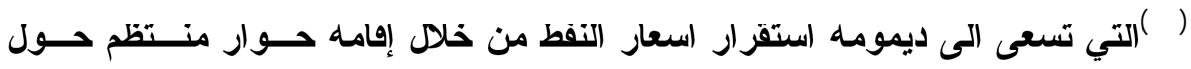
هضايا الطاهه مع الاول الخليجيه والتي تجد فيها روسيا ايضا سوها لمنتجاتها الصناعيه و العسكريه. وضلا عن استقطاب الاستتمار ات وبخاصه الممكه العربيه السعوديه (IV). 
يلخل التناصس الدولي ضمن محددات الاستراتيجيه الروسيه وهلا مــ يفسـر

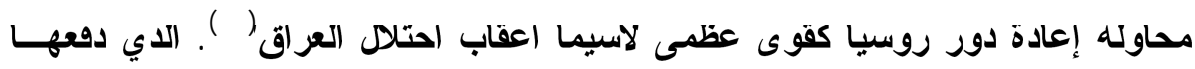

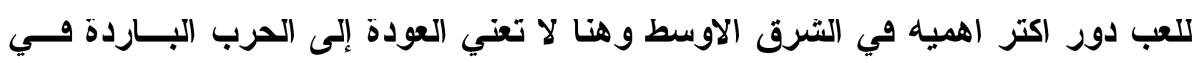

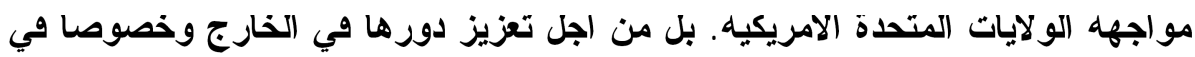
منطقه الخليج العربي التي تعتبر احد اهم مجالات توازن القوى العالميه(19). تالتا: مظاهر الإستر اتيجيه الروسيه في منطقه الخليج العربي تفعيل العلاهات مع دول مجلس التعاون الخليجي: لم يؤد تفكك الاتحاد السوفيتي في عام 1991 إلى التتوع في خيارات الــسياسه

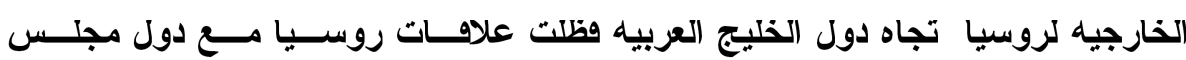

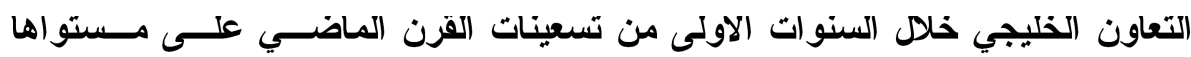

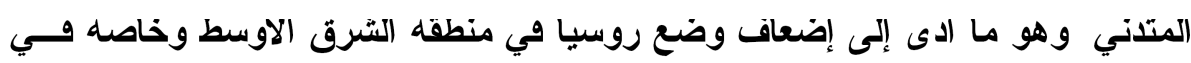
منطقه الخليج العربي أr). لم تجد علاهات روسيا ميع الوطن العربي دوعه هويه نحو التطور حتى حلول عــام

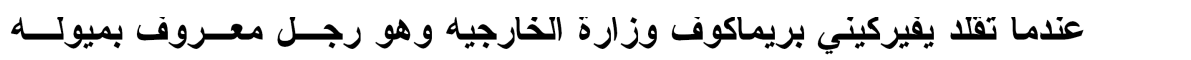

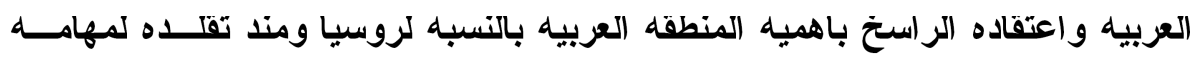

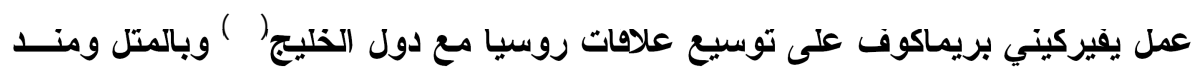

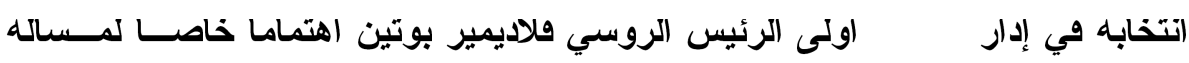

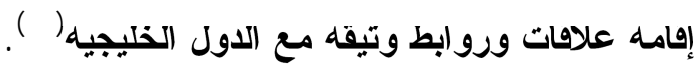

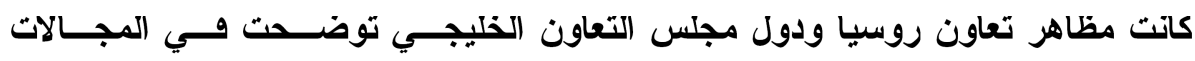
الاهتصاديه و السياسيه والامنيه و التقاهيه وكان مجال الطاهه من ابرز مظاهر التعاون بين الطرهين في ظل رئاسه هلاديمير بوتين. 
تصدرت الطافه اهم جواتب التعاون بين روسيا ودول مجلس التعساون الخليجـي

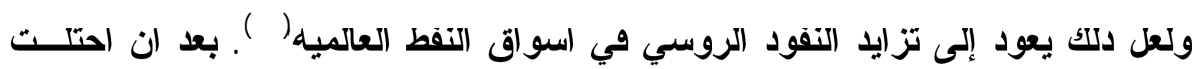
روسيا المرتبه التاتيه في فائمه الدول المصدرة للنفط بعد السعوديه إد تجــاوزت حجــ

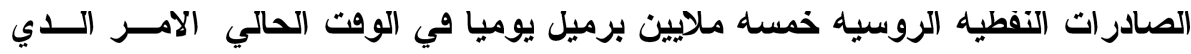

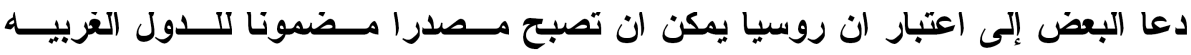

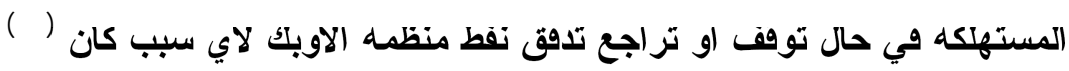
اصبح التعاون وي مجال النفط والغاز يشكل العنصر الرئيس في المباحتات التنائيه بين روسيا ودول مجلس التعاون الخليجي، خصوصا السعوديه التي كاتت الاكتر رغبه في التعاون مع روسيا من التنافس معها وي اسواق النفط الدوليه واتعكست هلده الرغبه بشكل جلي من خلال اتفاق التعاون الدي ووعه الجاتبان السعودي و الروسي خلال زيارة

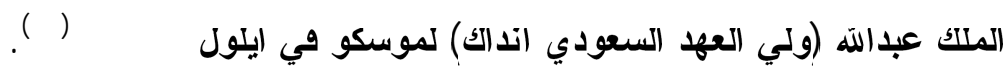

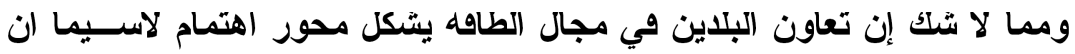

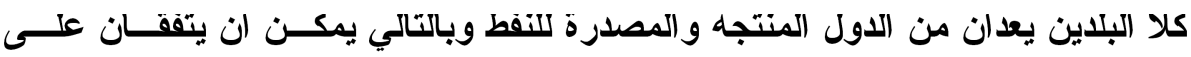
تتسيق سياستهما النفطيه ويكونان سببا في تحديا سعار النفط العالميه.

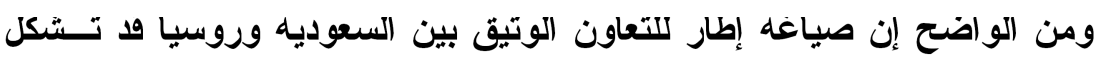

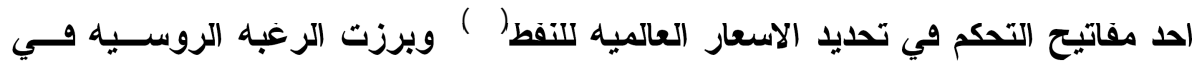
تعزيز اطر التعاون ميع دول مجلس التعاون في مجال الطاهه من خلال الاجندة الاهتصاديه التي تبتها روسيا تجاه دوله الإمارات وفطر والكويت وقامت الثركات الروسيه بالتوفيع

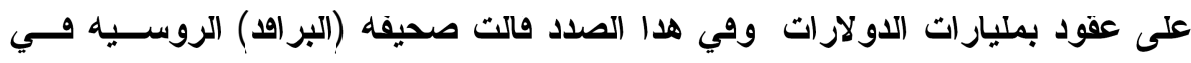

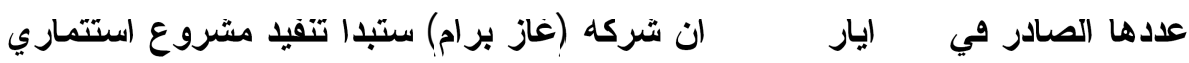

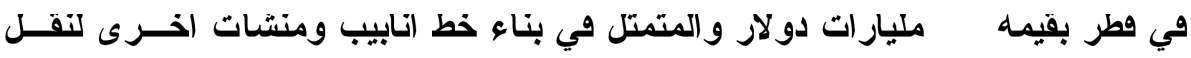

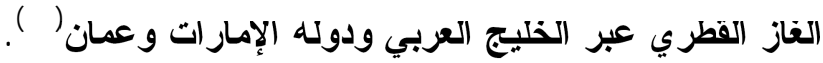

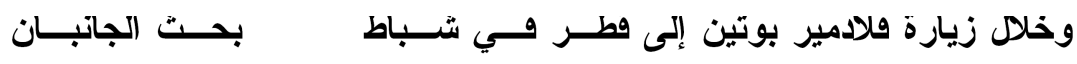
إستراتيجيه الطافه في المستقبل، وعلى وجه الخصوص فكرة إنسشاء منظمـهـ للــدول 
المصدرة للغاز على غرار منظمه (الاوبك) وكان هلا محور مباحتــات الـــئيس بوتين معه امير دوله فطر التي تعد تالت اكبر منتج للغاز وضد ظهر هدا الافتـراح لاول

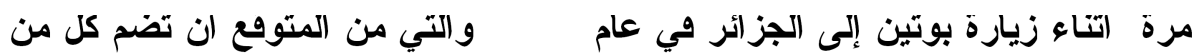

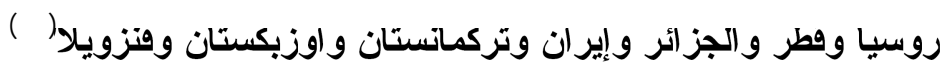
اما زيارة الرئيس الروسي بوتين للسعوديه وي شباط V V. V تم وقل التوفيع على عدد من الاتفاقيات بين الجاتبين احدها إطلاق سته اومار اصطناعيه للاتصالات وفي هده الزيارة صرح بوتين لرجال الاعمال سعوديين وروس انه يرى إمكاتيـهـه التعـاون مـــع

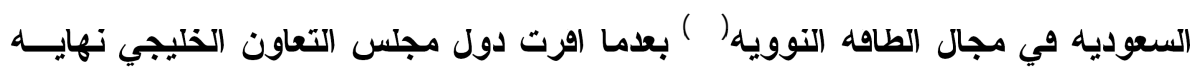

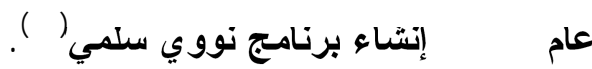
التعاون في مجال التجارة والاستتمار حضي موضوع توسيع العلاهات التجاريه والاستتمار في الصناعات الاساسـيه متل البتروكيماويات وتكرير النفط والمعادن والاغديه و الادويه و الكهرباء و المياه بقــدر

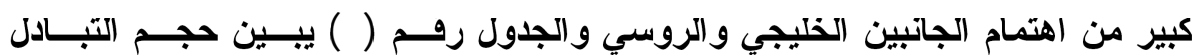

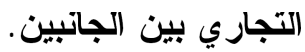

\begin{tabular}{|c|c|c|c|c|c|}
\hline \multicolumn{2}{|c|}{ 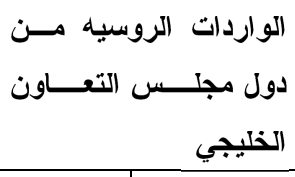 } & \multicolumn{2}{|c|}{ مجلس التعاون الخليجي الروسيه داتل } & \multicolumn{2}{|c|}{ بين الجانبين التبادل التجــاري } \\
\hline المعدل\%\% & القيمه & المعدل\%\% & القيمه & - & الدوله \\
\hline \% & 119 & $\%$ & 1.ro & I. દع & السعوديه \\
\hline- & - & - & - & זוץ & الإمارات \\
\hline$\% \cdot, v$ & سודالف & \% १и,г & 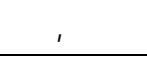 & 9. & عمان \\
\hline- & - & - & - & EOrr & وطر \\
\hline- & - & - & - & Irqץ & البحرين \\
\hline- & - & - & - & - & الكويت \\
\hline
\end{tabular}

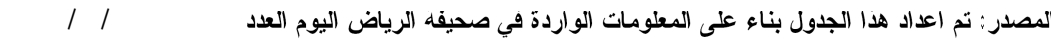

\section{http://www.aliyadh.com.content30/1/2003}




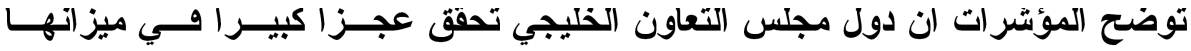

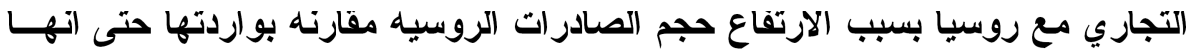
تمتل حوالي \\$\%من إجمالي تجارة روسيا مع الدول الخليجيه. يتسم التعاون الروسي الخليجي في الاستتمارات بالضعف حيث لا تتجاوز فيمه الاستتمارات الخليجيه وي روسيا . . I مليون دولار ويما يلاحظ تلني فيمه الاستتمارات الروسيه وي دول مجلس التعاون الخليجي باستتناء مشروعات معدودة من بينها مشروع

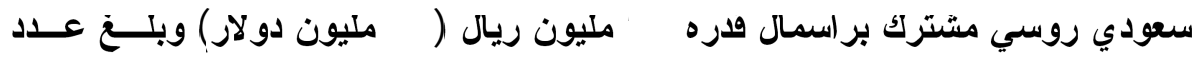
الوكالات التجاريه الروسيه المسجله وي البحرين ع وكالات وتغطي مجالات الشحن وبيع وحجز تلاكر الطيران وهناك بعض الشُركات المحدودة العامله في البحرين مع اطـــراف

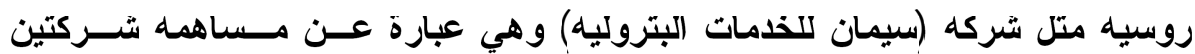

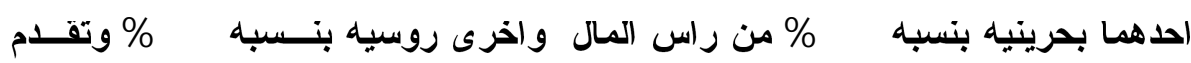

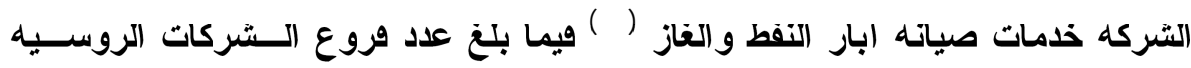

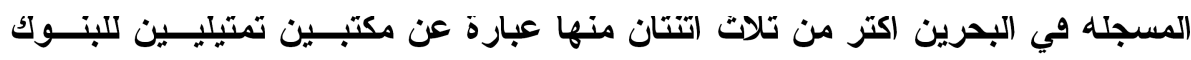

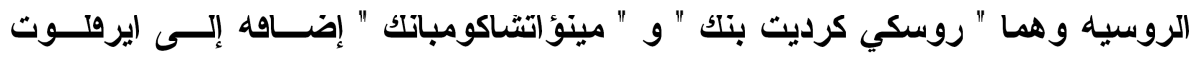

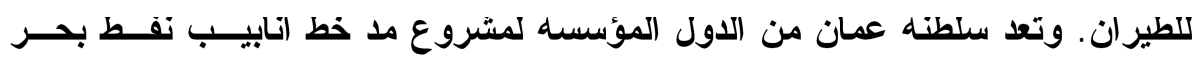
وزوين والدي يمر من خلاله النفط الكازاخستاني عبر الاراضي الروسـيه إلــى مينــاء نوهودسيك الروسي على البحر الاسود و وتثارك ويه تلاث دول هي روسيا وكازاخستان

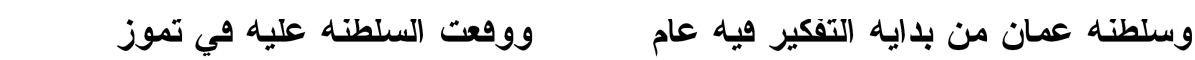

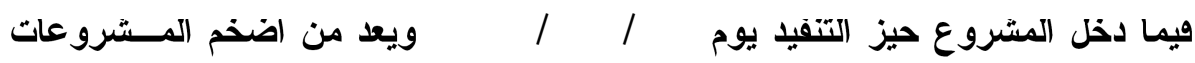

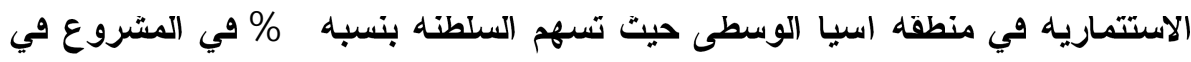

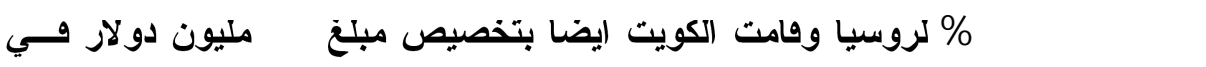
اب 1997 للمساهمه في اعمار مرها موماشك في شمال روسيا (IT). 
التعاون في قضايا السياسية الإقليمية والعالمية شـهلت المرحله وبل وبعد عام Y . . م تعاون متبادل بين روسيا ودول مجلـس التعاون الخليجي في المجالات السياسيه وتجسدت اهم جوانب الاهتمام في مساله تتسيق

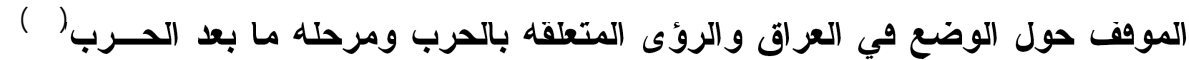
هقد اتخلت حكومه فلادمير بوتين موهفا رافضا للحرب التي فادتها امريكا على العسراق

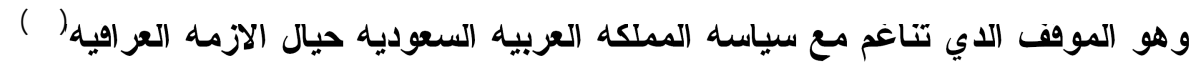
وولد ولدت روسيا مبادرة عقد مؤتمر دولي حول العراق باشتراك كل البلـــان المعنيـهـه

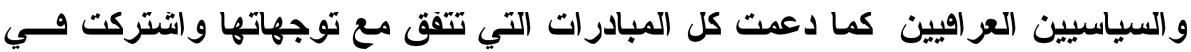
مؤتمر شرم الشيخ وي تشرين التاني ع. .م الادي عقد بمصر وايدت مبــادرة جامعسه الدول العربيه لعقد اجتماع بين ممتلي الاتجاهات العراويه والاحزاب العياسيه الرئيسـسه. تمهيدا للوصول إلى المصالحه الوطنيه(ro). وخلال زيارة الرئيس الروسي فلادمير بوتين الى المملكه العربيه السعوديه وــي

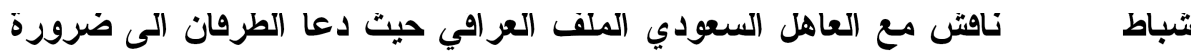

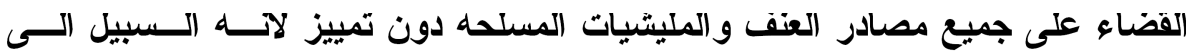
تحقيق الوحدة الوطنيه بين جميع مكونات الثبع العر اهي (r7).

اما الملف النووي الإيراني ويحتل مكاته مهمه في المباحتــت بـين روسـيا

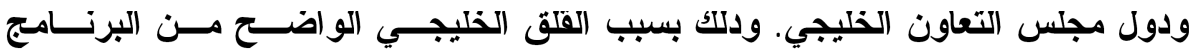
وانعكاساته وي حاله حدوث حرب امريكيه هلا من جهه، ونظرا للتاتير الروسـي علـى ونى

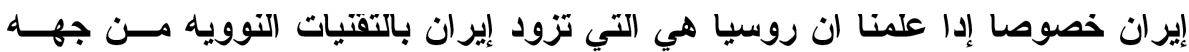
(اخرى) ("rv).

لالك نرى ان روسيا دائما تسعى التطمين دول مجلس التعاون الخليجي ويتـضح دلك من خلا تصويتها على فرار مجلس الامن روم IVYY الصادر في سم كانون الاول

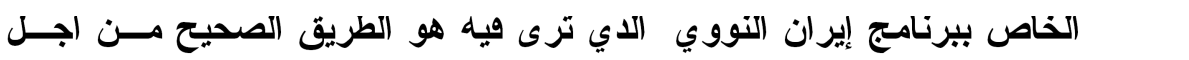

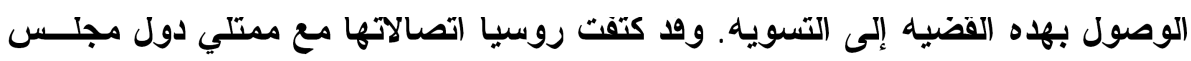
التعاون الخليجي، الدين يؤيلون إيجاد حل بالطرق السلميه للقضايا القائمــهـه والمتعلقــهـه

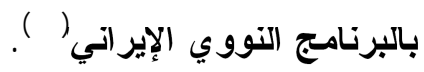

كما التقى الموهف الخليجي الروسي في بشان ما يجري في لبنان وفلسطين. إد

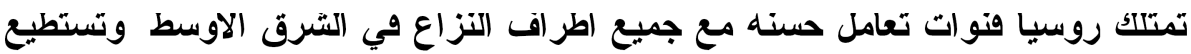


من خلاده العمل على تقريب وجهات نظر من اجل حل المشاكل العالقه بين الاطراف كما ان دول مجلس التعاون الخليجي وخاصه المملكه العربيه السعوديه دورا نشطا جدا هـي معالجه الوضع وي لبنان واسهمت إسهاما بارزا في تطبيع الاوضاع وي ولسطين ("9). ودعمت روسيا التحقيق الدولي وي وضيه اغتيال رويق الحريري وصوت ممتلهبـا

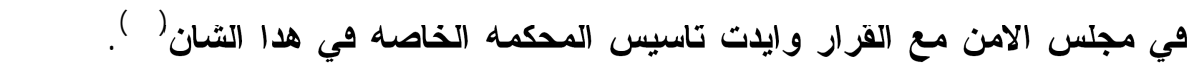

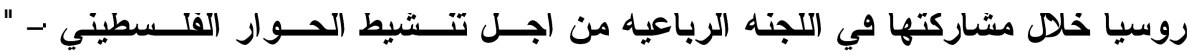
الإسر ائيلي". و اكلات على ضرورة وهق المواجهات الفلسطينيه من خلال دعم الحوار بين لين تتح وحماس.وتدوع من اجل عقد مؤتمر دولي خاص بقضايا الشرق الاوسط, لالك تبال

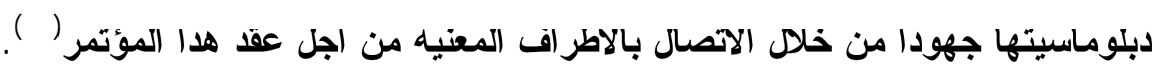
وعكست الاجتماعات المتعددة التي عقدها المسئولون الروس والخليجيون خلهن

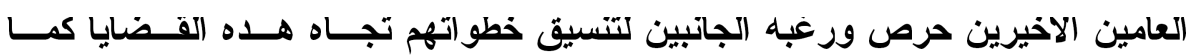
اظهرت تشابه الرؤى بين دول الخليج العربيه وروسيا حول مسائل متعددة متل الحفــاط

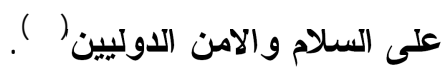

استثمار فتور العلاقات الخليجية الأمريكية بعد أحداث أيلول شـهـت العلاهات بين دول مجلس التعاون الخليجي والولايات الامريكيـه بعـض التوترات وخاصه المملكه العربيه السعوديه التي تعرضت في إطار تلكـ التوترات لحملــهـ

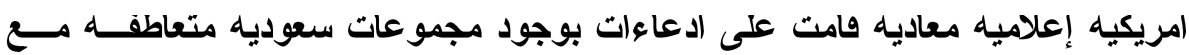
تتظيم القاعدة، وتورط بعض المسؤولين في الحكومه السعوديه في عمليات دعم وتمويل

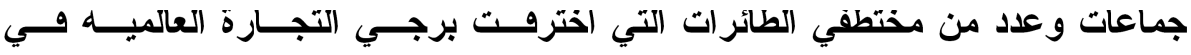

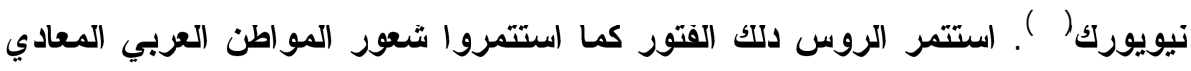
للو لايات المتحدة الامريكيه. الدي يرى فيها دوله مناهضه لقضايا العرب والمسلمين من لهن خلال مواقفها المنحازة وي الصراع العربي الصهيوني لصالح" إسرائيل " مرورا باحتلال اقغانستان واحتلال العراق.

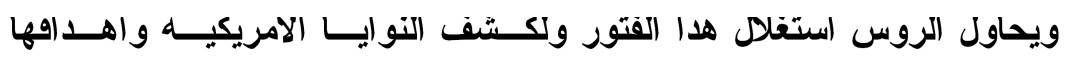

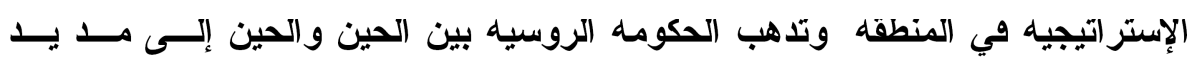


الصداهه و التعاون مع دول الخليج في جميع المجــالات لفـرض تنفيـــ الإســتراتيجيه الروسيه، ولالك تسعى دول مجلس التعاون إلى تلعيم علاهاتها مع روسيا وهو بالتاكيا ليس على حساب علاهاتها مع الولايات المتحدة الامريكيه وهله علاهات اساسيه وبخاصه إن الطرف الاخر ويها هو القطب الواحد في مرحله ما بعد الحرب الباردة. وهنا لابد من التاكيل على حقيقه هامه وهي ضرورة التمييز بين الاستر اتيجيه والتكتيك في توجهــات

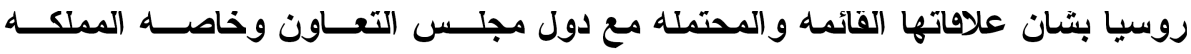
العربيه السعوديه.

روسيا وإمكاتية الانضمام إلى منظمة سعت روسيا من اجل الانضمام إلى منظمه المؤتمر الإسلامي ولو بصفه مراهـب

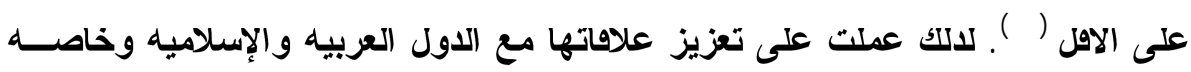

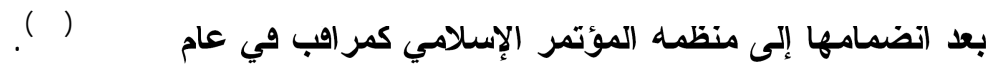
ومما لاشكك ويه ان روسيا تستتمر انضمامها إلى المنظمه في ما يتعلق بالقضيه

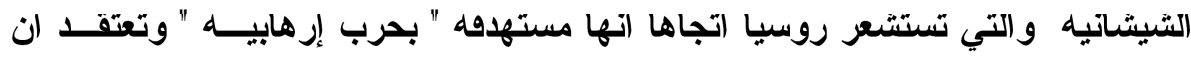
التعاون السياسي الفعال ميع اوطار الخليج وبالخاص المملكه العربيه السعوديه سيـسـاعد

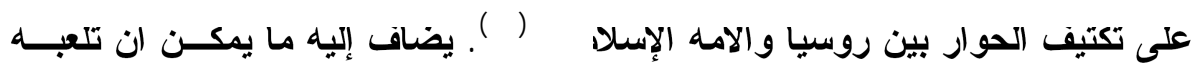

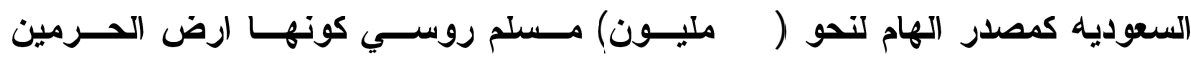

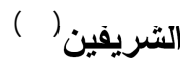
عملت روسيا على عقد سلسله مؤتمرات حول روسيا والامه الإسلاميه والـــي

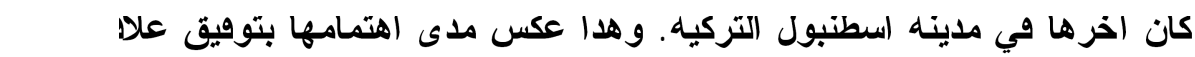

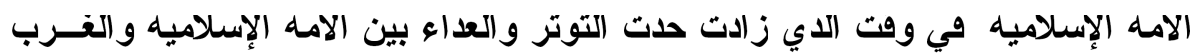

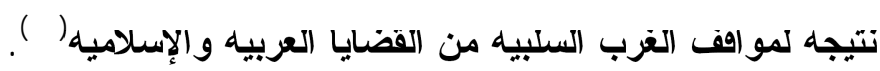

إن التقام الدي حقفته روسيا في السنوات الاخيرة وفي ظل رئاسه ولادمير بوتين في منطقه الخليج العربي كان نتيجه تماسك الدوله التي كاتت مهلدة بالتفكك من الداخله وتحسين الوضع الاوتصادي لها وحدوث تغير جوهري في دينامكيـة صــنع السـياسه

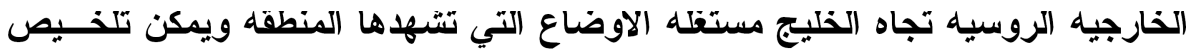


[ro9] عبد الرز اق خلف محمد الطائي

العوامل التي هيات نجاح الابلوماسيه الروسيه لتحقيق إستراتيجيتها تجاه منطقه الخليج العربي في ما ياتي: - التيات

- تسجيل بعض الفتور وي العلاهات بين دول مجلـس التعــاون والولايــات المتحــدة الامريكيه. - تبات موفف روسيا من الصراع العربي الإسرائيلي ورغبتها وي التوصل إلـى حـل نهائي لازمه الشرق الاوسط.

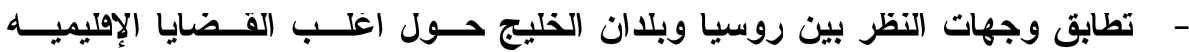
و الدوليه.

- استخدام روسيا موارد الطاهه بالشكل الآسب وضلا عن موارد التكنولوجيا النوويـهـ وتعزيز علاهاتها مع جميع الإطر اف الإفليميه الرئيسيه في المنطقه.

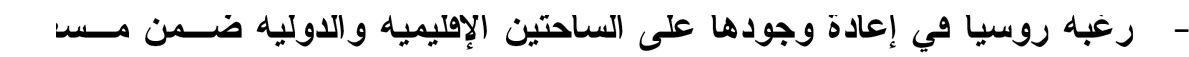
لتاسيس نظام عالمي متعدد الاوطاب حسب إعلان بوتين في زيارة الاخيرة للهند. إن العوامل السابقه يمكن ان تجعل من روسيا طرها مهما وي الخليج ميع امريكا.

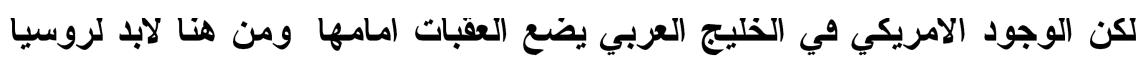

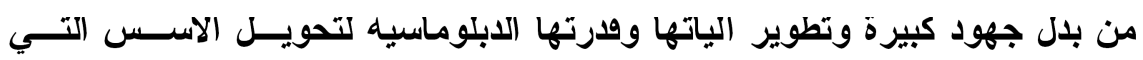
وضعها الدبلوماسيون الروس ونظراؤهم الخليجيون خلال السنوات الاخيرة لشراكه راسخه تخدم مصالح جميع الاطر اف المعنيه. 


\title{
Arab Gulf In Contemporary Russian Strategy
}

\begin{abstract}
Abdul Razzaq Kh. M. Ibrahim. Altai* Abstract

The basic dimensions and main limitations in Russian Strategy during the reign of president Fladermair Butin towards states of Gulf Cooperation Council are rearrested by both Security element and economic element. Russia Sees that challenges represented by Islamic groups may threaten its Security. Thus, the issue of chines is emerged and the existence of 20 million Muslims living inside Russia Therefore، Russia tries to establish relations with Gulf states especially Saudi Arabia which has a big influence upon these groups.

Russia tries to attract investments from these States making an organized dialogue concerning energy and oil prices and trying to activate its relations with Gulf States in all fields in order to achieve its goals in the Arab Gulf Area.
\end{abstract}

*Assist. Lecturer, Dept. OF Political And Strategic Studies, Regional Studies

Center, Mosul University. 
المصادر والهوامش

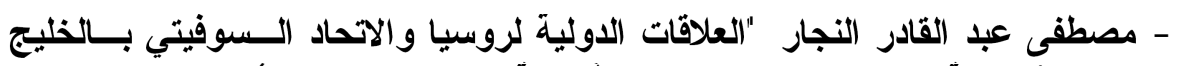

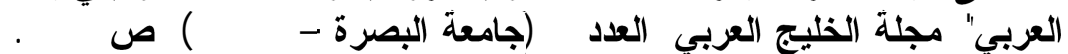

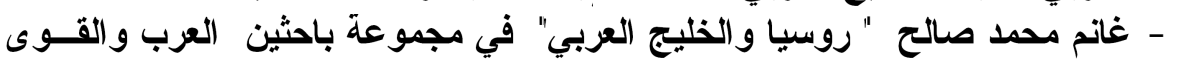

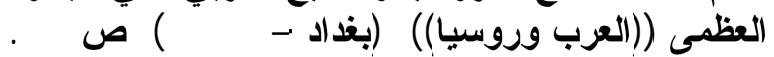

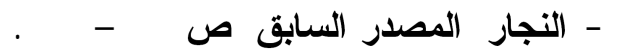

ع - 0

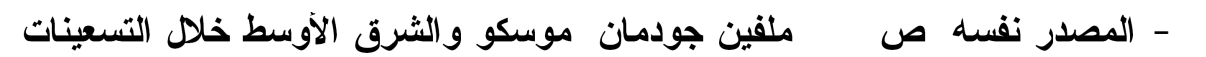

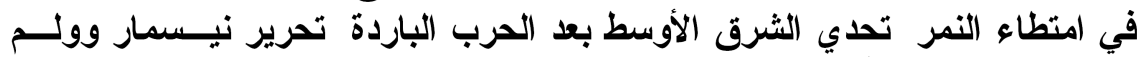

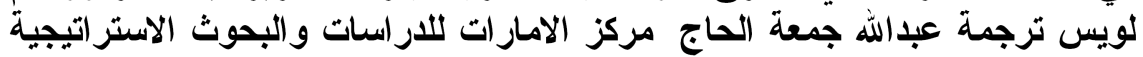

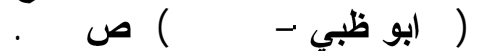

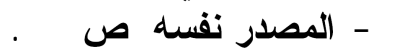

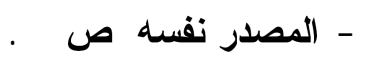

$$
\begin{aligned}
& \text { A - صالح، المصدر السابق، ص } 99 \text { - } 99 .
\end{aligned}
$$

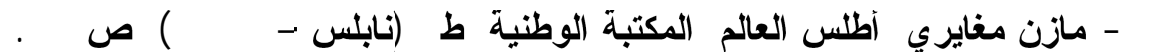

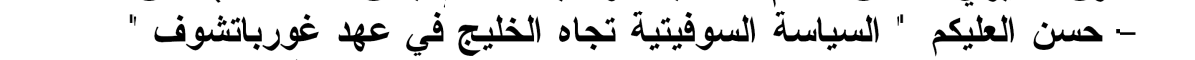

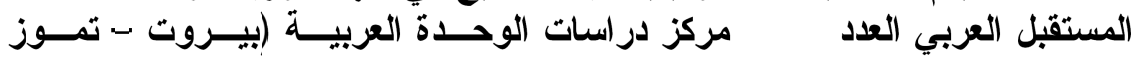

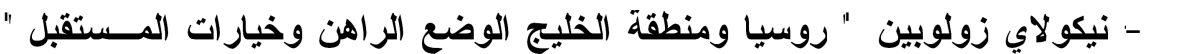

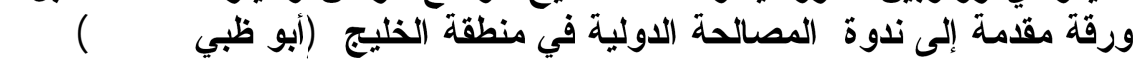

Http://www.alriyadh.com

$$
\text { موقع }
$$

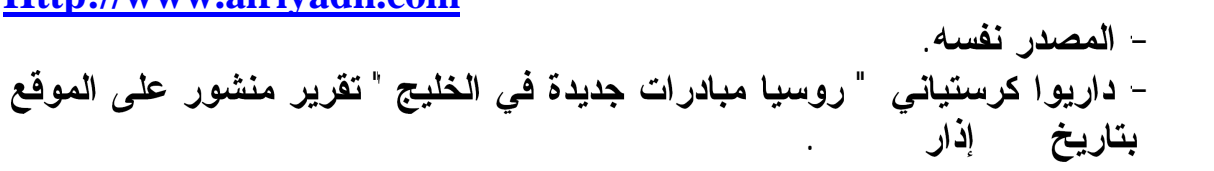

http://www.Pinrcom-reportphpac=iewreport

$$
10 \text { - } 17 \text { - العليكم، - زولوبين، المصدر السدابق، السابق. } 1 \text { - زولوبين، المصدر السابق. }
$$

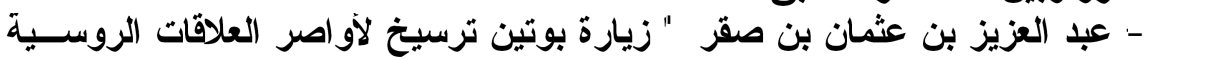

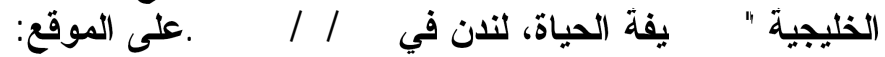

http://www.pinr.com-report.phans

$$
19 \text { - كردستياني، المصدر السابق. }
$$


• r -اليلا أكيرمان،" العلاقات بين دول المجلس وروسيا في مجموعة باحثين الخليج في

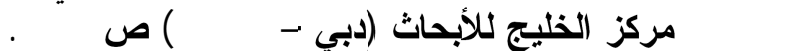

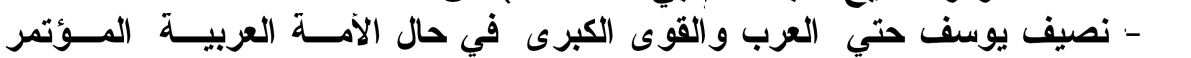

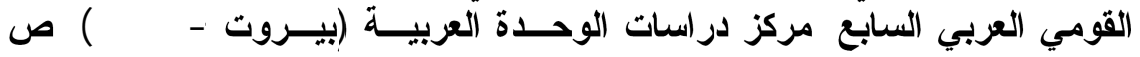
. 17 r

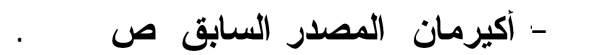

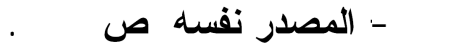
عr - السير سيد الحمد،" العلاقات السعودية الروسية من التنافس إلى التعاون "،صحفية

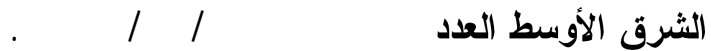

http://www.asharaalawsat.com

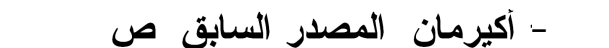

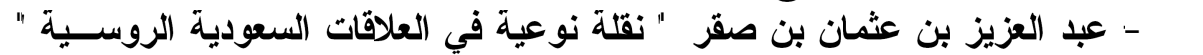

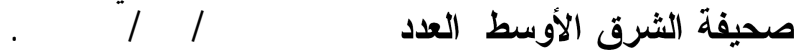

http://www.asharaalawst. com

$$
\text { - أكيرمان، المصدر السابق - YV }
$$

28-Victor yasmann،" Patin use Gulf Trip To Boost Russian Role in Arab World

" Radio Free Europe / 13 / / 2007

http- www. Rferl org-featuresarticle - 2007-2 - 1

http://www.Daratlayat.htm

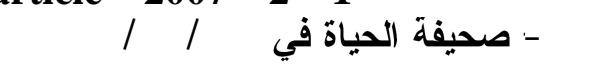

· - البيان الختامي لقمة مجلس التعاون لاول الخليج العربي الاورة السابعة و العشرون

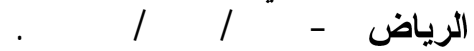

http://www.gcc-sg. org/report27htm

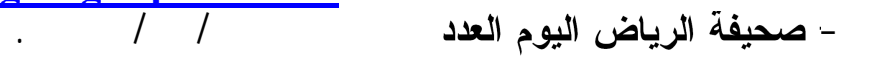

http://www.alriyadh.com.content30/1/2003

$$
\text { rוץ - المصدر نفسه. }
$$

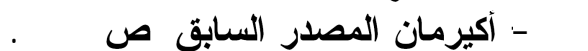

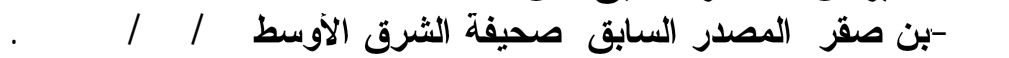

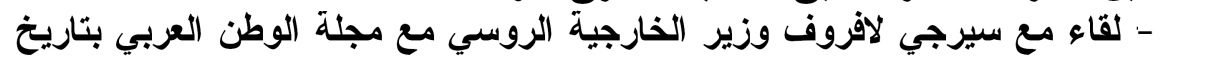

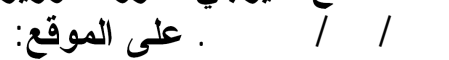

http://www.alqanat.com/news/shownews >asp?id=78339

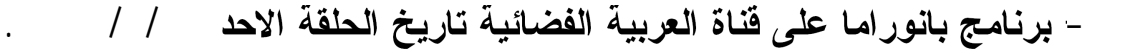
http://www.alarabiya.net

$$
\begin{aligned}
& \text { NV - المصدر نفسه. } \\
& \text { A M - لقاء ميع وزير الخارجية الروسي، المصدر السابق. } \\
& \text { q } \text { - المصدر - نفسه. }
\end{aligned}
$$

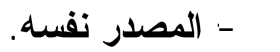

$$
\begin{aligned}
& \text { اع - المصدر نفسه. }
\end{aligned}
$$


[rir]

عبد الرزاق خلف محمد الطائي

مع - للمزيد من المعلومات ينظر الوثائق المنـشورة عـن وزارة الــصحافة والإعـلام

$$
\text { الروسبية - لاليز من }
$$

http://www.mid.ru

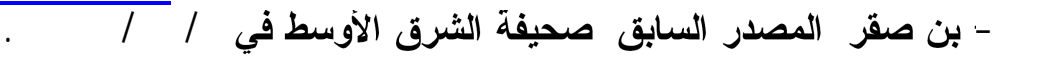

$$
\begin{aligned}
& \text { ع ع - المصدر نفسهة. }
\end{aligned}
$$

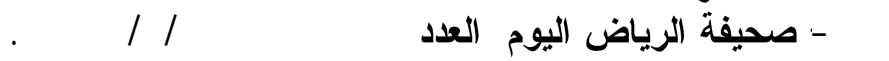

http: //www. Alriyadh- np. Com

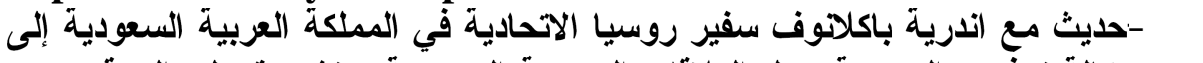

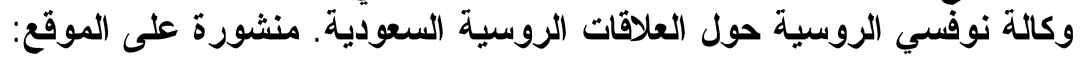

http: //www rullarabru / rusions. htm

$$
\begin{aligned}
& \text { ع ع - سيد احمد، المصدر السابق. }
\end{aligned}
$$

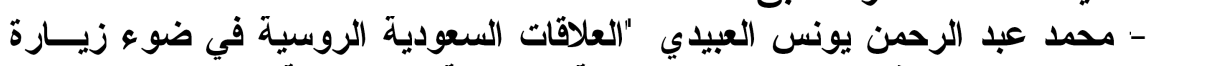

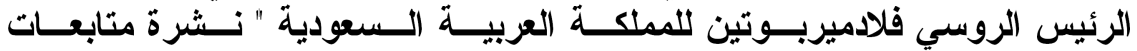

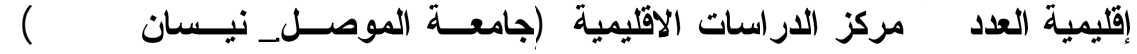

$$
\begin{aligned}
& \text { ص0. }
\end{aligned}
$$

